\title{
A questão da responsabilidade socioambiental na reciclagem de plástico no Rio de Janeiro
}

\author{
Marco Antonio Gaya de Figueiredo ${ }^{\mathrm{a}, *}$, Alberto Chenú Deorsola ${ }^{\mathrm{b}}$ \\ a,*mgaya@uerj.br, UERJ, Brasil \\ balbertocdeorsola@hotmail.com, UERJ, Brasil
}

\begin{abstract}
Resumo
Este trabalho objetivou verificar como as atividades de reciclagem impactam nas áreas de saúde, segurança e meio ambiente, levantando também algumas questões relacionadas com a responsabilidade social, com destaque para o atendimento às normas regulamentadoras, legislação de saúde, segurança e meio ambiente aplicáveis. 0 questionário elaborado foi aplicado diretamente a um grupo de recicladoras, todas situadas no estado do Rio de Janeiro, sendo três do segmento de polietileno e uma de politereftalato de etileno. Verificou-se que apenas 24\% dos itens avaliados foram atendidos na sua íntegra, demonstrando um baixo índice de atendimento às questões relativas à saúde, segurança, meio ambiente e responsabilidade social. Enfim, o presente estudo mostra que há necessidade de maior atenção por parte do poder público quanto à criação de uma infraestrutura de capacitação de forma a permear essas informações para os profissionais que atuam nesse segmento.
\end{abstract}

Palavras-chave

Reciclagem. Plástico. Saúde. Segurança. Meio ambiente. Responsabilidade social.

\section{Introdução}

A questão da logística de reprocessamento de resíduos tem sido um problema constante nas diferentes pautas ligadas à gestão de saúde, segurança e ao meio ambiente dos estados e municípios da nossa federação. Um grave problema encontrado é a baixa conscientização dos diferentes atores envolvidos. A sociedade, de forma geral, tem grande dificuldade em conscientizar-se da efetiva necessidade da separação dos diferentes tipos de resíduos gerados no dia a dia. Por outro lado, as autoridades não disponibilizam recursos para uma implantação de coleta seletiva, por parte dos que vivem da coleta de material descartado, seja nas ruas ou nos aterros sanitários. Essas pessoas, por terem normalmente baixo conhecimento ou escolaridade (quando têm alguma), estão constantemente expostas a todo o tipo de problemas de saúde, pois não possuem núcleos de informação para receber conhecimentos elementares na área da saúde e segurança. No final desse segmento estão as unidades de reciclagem - uma atividade ainda marginal -, que não sofrem efetiva cobrança por parte dos diferentes órgãos de fiscalização e também não divulgam as informações nem disponibilizam recursos para que a atividade seja realizada dentro das condições aceitáveis em termos de saúde, segurança e meio ambiente.

O Brasil produz 100.000 t de lixo por dia. A metrópole de São Paulo gera 15.000 t diárias, um volume que, prensado, equivaleria a um prédio de 30 andares. Tudo é recolhido e depositado em aterros (ARERJ, 2009).

A respeito da reciclagem de papel, pesquisas realizadas por Terasaki et al. (2008) mostram que o efluente gerado no processo tem oito tipos de poluentes, em particular, aril-hidrocarbonetos, incluindo alguns cloretos de aril-éter até então não identificados como poluentes aquáticos, em concentrações de $1600 \mu \mathrm{g} \cdot \mathrm{l}^{-1}$ e $190 \mu \mathrm{g} \cdot \mathrm{g}^{-1}$. Rix et al. (1997) mostram a ocorrência de riscos de câncer nos trabalhadores desse mesmo segmento no caso da reciclagem de baterias. Paoliello e De Capitani (2007) verificaram que a legislação é inadequada, pois estabelece um nível de $60 \mu \mathrm{g} / 100 \mathrm{ml}$ de chumbo no sangue (Índice Biológico Máximo Permissível - IBMP) como um limite seguro, enquanto a Conferência Americana da Indústria de Higiene Governamental (ACGlH) determina um limite mais baixo: $30 \mu \mathrm{g} / 100 \mathrm{ml}$ de chumbo no sangue. 
No que se refere ao segmento de plásticos em geral, Pereira (2006) mostra que os principais impactos à saúde, à segurança e ao meio ambiente identificados na reciclagem de politereftalato de etileno (PET), no Estado do Rio de Janeiro, são alterações da paisagem, das condições dos corposd'água, da vida útil dos aterros, da qualidade dos lençóis freáticos, das emissões atmosféricas, do ruído e dos riscos à saúde pública e danos à saúde dos catadores (GUTBERLET; BAEDER, 2008).

Diante desse cenário, buscou-se neste trabalho verificar como as atividades de reciclagem estão sendo realizadas sob o foco da saúde e segurança do trabalhador. Para tal, calcado no material pesquisado sobre responsabilidade socioambiental, focando as áreas de saúde, segurança e meio ambiente, elaboraram-se questionários que foram aplicados a empresas de reciclagem de médio e pequeno porte para identificar a situação destas em relação aos segmentos apresentados. Optou-se por se trabalhar no segmento de plásticos, principalmente na linha de polietileno de alta e baixa densidade (PEAD/PEBD), polipropileno (PP) e polietileno tereftalato (PET) por se tratar dos que mais impactam o meio ambiente de forma geral.

\section{Legislação ambiental}

A legislação ambiental no Brasil é considerada uma das mais restritivas se comparada com países desenvolvidos. São várias as resoluções e leis que concorrem para a garantia da qualidade seja da segurança ocupacional como da questão ambiental, por exemplo, a Resolução $n^{\circ}$ 237, do CONAMA, (BRASIL, 1997) determina os procedimentos e critérios utilizados no licenciamento ambiental, a Diretriz DZ-205.R-5 (INEA, 1991) estabelece, como parte integrante do Sistema de Licenciamento de Atividades Poluidoras - SLAP, exigências de controle de poluição das águas. Há também a Lei n. ${ }^{\circ}$ 9.605, de 12 de fevereiro de 1998, Lei de Crimes Ambientais, (BRASIL, 1988) que dispõe sobre as sansões penais e administrativas derivadas de condutas e atividades lesivas ao meio ambiente, e estabelece outras providências.

Já o Sistema Municipal de Licenciamento Ambiental da Cidade do Rio de Janeiro, aprovado pelo Decreto Municipal $n^{\circ} 28.329$ de 17 de agosto de 2007, (RIO DE JANEIRO, 2007) é constituído por cinco tipos de licenças que dependem dos tipos de atividades e empreendimentos bem como de seu porte, e também da fase em que se encontra sua implantação, a saber: Licença Municipal Simplificada (LMS) -, destinada às atividades de pequeno porte e baixo potencial de impacto ambiental; Licença
Municipal Prévia (LMP) -, documento expedido na fase inicial do empreendimento a partir da adequação do projeto às regras de zoneamento e normas de uso e ocupação do solo, e que estabelece os requisitos básicos e condicionantes a serem obedecidos nas fases de instalação e funcionamento; licença Municipal de Instalação (LMI) -, autoriza o início da implantação do empreendimento ou atividade subordinando-o às condições de localização, instalação, operação e outras expressamente especificadas; Licença Municipal de Operação (LMO) -, expedida após a verificação do cumprimento das condições da LMI, autoriza a operação da atividade, desde que respeitadas as condições determinadas para a operação, e a Licença Municipal de Desativação (LMD) -, que deve ser requerida por todos os empreendimentos e atividades sujeitos à Licença Municipal de Operação, por ocasião do encerramento de suas atividades.

\section{Normatização}

No Brasil, o conceito de prevenção de acidentes, essencial aos aspectos normativos de gestão de saúde e segurança do trabalho, já era conhecido pelas organizações brasileiras desde o final da década de 70, em função das exigências das Normas Regulamentadoras (NR), do Ministério do Trabalho, estabelecidas a partir da Portaria $n^{\circ}$ 3.214/78, (BRASIL, 1978) relativas à segurança e medicina do trabalho. Essas normas são de observância obrigatória pelas empresas brasileiras, de caráter publico ou privado, pelos órgãos públicos da administração direta e indireta, bem como pelos órgãos dos Poderes Legislativo e Judiciário que possuam empregados regidos pela Consolidação das Leis do Trabalho (CLT).

Já no campo das normas internacionais aplicáveis na área de saúde, segurança e meio ambiente encontramos a norma da Occupational Safety Health Administration OHSAS 18001:2007 (OHSAS, 2007) que estabelece que a organização deve documentar, implementar, manter e melhorar continuamente um sistema de gestão da segurança e saúde no trabalho. Na área ambiental, a Norma Brasileira NBR 1S014001:2004 (ABNT, 2004b) determina os princípios a serem seguidos para um sistema de gestão ambiental. No caso da responsabilidade social, apesar de ser uma área que ainda está sendo inserida na cultura gerencial, temos como normas internacionais a norma SA8000:2008 - Social Accountability, desenvolvido pela Social Accountability International (SAl, 2008), organização não governamental criada em 1997 nos Estados Unidos, e que tem ação voltada à preocupação dos consumidores quanto 
às condições de trabalho no mundo. A norma faz menção às condições de trabalho, dentre elas: mão de obra infantil, trabalho forçado, saúde e segurança, liberdade de associação e de negociação coletivas, discriminação, práticas disciplinares, carga e horário de trabalho e remuneração. No Brasil a NBR 16001:2004 (ABNT, 2004a) trata da questão relacionada à responsabilidade social, porém não estabelece critérios absolutos de desempenho, além daqueles comprometidos com a política de gestão da responsabilidade social e com melhoria contínua; já a norma SA8000:2008 (SAl, 2008) determina critérios absolutos de desempenho quando apresenta os seus requisitos.

\section{Metodologia}

Para a identificação do quadro relacionado ao atendimento dos princípios legais e normativos ligados às áreas de saúde, segurança, meio ambiente e responsabilidade social junto às empresas de reciclagem de plástico, baseado na pesquisa das diferentes fontes consultadas, foi elaborado um questionário onde se buscou primeiramente identificar os dados das empresas. Em seguida foram elaboradas perguntas relativas às questões legais concernentes ao meio ambiente, seguidas de questões ligadas à responsabilidade social e, para complementar, questões relacionadas a aspectos de saúde e segurança.

Como o foco do trabalho estava na área de reciclagem de plásticos foram contatadas apenas as empresas presentes nos cadastros da Associação dos Recicladores do Estado do Rio de Janeiro (ARERJ) e do Compromisso Empresarial para a Reciclagem (CEMPRE). De acordo com o site do CEMPRE, existem:

- 24 recicladores de plástico no município do Rio de Janeiro

- 76 recicladores de plástico no Estado do Rio de Janeiro

\section{- 859 recicladores de plástico no Brasil}

A pesquisa focou apenas os recicladores instalados no município do Rio de Janeiro. Foram realizados contatos com um número significativo de empresas, porém apenas quatro concordaram com a pesquisa (uma de reciclagem de PET e três de reciclagem de polietileno de baixa densidade PEBD). Apesar de o número de empresas pesquisadas corresponder a $16 \%$ do total, o resultado servirá como base para avaliar a situação do segmento quanto aos aspectos de saúde, segurança e meio ambiente.

Quadro 1. Critérios de aceitação.

\begin{tabular}{|c|c|c|}
\hline $\begin{array}{l}\text { Considerou-se o item } \\
\text { "Atendido (A)", } \\
\text { se a empresa possui: }\end{array}$ & $\begin{array}{c}\text { Considerou-se o item } \\
\text { "Atendido Parcialmente (AP)", } \\
\text { se a empresa: }\end{array}$ & $\begin{array}{l}\text { Considerou-se o item } \\
\text { "Não Atendido (N)", } \\
\text { se a empresa não possui: }\end{array}$ \\
\hline Plano de emergência formal. & $\begin{array}{l}\text { Possui plano de emergência em fase de } \\
\text { implantação, ou não tem profissionais } \\
\text { treinados para atender às emergências. }\end{array}$ & Plano de emergência. \\
\hline $\begin{array}{l}\text { Programa de Prevenção de Riscos } \\
\text { Ambientais (PPRA) e Programa de } \\
\text { Controle Médico e Saúde Ocupacional } \\
\text { (PCMSO) formais. }\end{array}$ & $\begin{array}{l}\text { Possui programas PPRA e PCMSO formais, } \\
\text { porém não possibilitam a identificação e } \\
\text { avaliação dos riscos. }\end{array}$ & Programas PPRA e PCMSO. \\
\hline $\begin{array}{l}\text { Controle de todas as emissões e dos } \\
\text { resíduos sólidos gerados no processo. }\end{array}$ & $\begin{array}{l}\text { Controle das emissões atmosféricas não } \\
\text { contempla todas as emissões ou está em } \\
\text { fase de implantação e o programa de } \\
\text { gerenciamento não contempla todos os } \\
\text { resíduos sólidos gerados no processo. }\end{array}$ & $\begin{array}{l}\text { Controle das emissões atmosféricas } \\
\text { e programa de gerenciamento dos } \\
\text { resíduos sólidos/disposições. }\end{array}$ \\
\hline $\begin{array}{l}\text { Serviço Especializado em Engenharia } \\
\text { de Segurança e em Medicina do } \\
\text { Trabalho (SESMT) e/ou Comissão } \\
\text { lnterna de Prevenção de Acidentes } \\
\text { (CIPA) constituídos. }\end{array}$ & SESMT e/ou CIPA em fase de constituição. & SESMT e/ou CIPA \\
\hline $\begin{array}{l}\text { Plano de manutenções corretivas e } \\
\text { preventivas formalizado. }\end{array}$ & $\begin{array}{l}\text { Possui o plano de manutenção corretiva, } \\
\text { ainda que informal e em fase de implantação. }\end{array}$ & $\begin{array}{l}\text { Plano de manutenções corretivas e } \\
\text { preventivas (mecânico e elétrico). }\end{array}$ \\
\hline $\begin{array}{l}\text { Evidência de fornecimento de } \\
\text { Equipamento de Proteção lndividual } \\
\text { (EPI) aos funcionários com certificado } \\
\text { de aprovação, registro de treinamento } \\
\text { quanto ao uso e conservação dos } \\
\text { EPls, bem como uma metodologia de } \\
\text { fiscalização quanto ao seu uso. }\end{array}$ & $\begin{array}{l}\text { Evidência de fornecimento de EPI aos } \\
\text { funcionários com certificado de aprovação, } \\
\text { porém sem registro de treinamento quanto ao } \\
\text { uso e conservação deles ou ausência de uma } \\
\text { metodologia de fiscalização quanto ao uso. }\end{array}$ & $\begin{array}{l}\text { Evidência de fornecimento } \\
\text { de EPl aos funcionários com } \\
\text { certificado de aprovação, registro } \\
\text { de treinamento quanto ao uso } \\
\text { e conservação deles, bem como } \\
\text { uma metodologia de fiscalização } \\
\text { quanto ao uso. }\end{array}$ \\
\hline
\end{tabular}


Tabela 1. Produção anual por empresa e número de empregados/terceiros por segmento de plástico.

\begin{tabular}{lccc}
\hline Empresas & $\begin{array}{c}\text { No de empregados/terceirizados } \\
\text { Masc./Fem. }\end{array}$ & $\begin{array}{c}\text { Segmento de plástico } \\
\text { (t/ano) }\end{array}$ \\
\hline Empresa A & $7 / 15$ & PEBD & 300 \\
Empresa B & $44 / 6$ & PEBD & 1.440 \\
Empresa C & $60 / 5$ & PEBD & 1.800 \\
Empresa D & $31^{*} / 25$ & PET & 5.640 \\
\hline
\end{tabular}

*Incluído um menor aprendiz do sexo masculino.

Tabela 2. Situação das empresas na área ambiental.

\begin{tabular}{|c|c|c|c|c|}
\hline \multirow{2}{*}{ Área de meio ambiente } & \multicolumn{4}{|c|}{ Situação das empresas* } \\
\hline & A & AP & $\mathrm{N}$ & NA \\
\hline A empresa possui licença de operação? & 25 & 75 & - & - \\
\hline $\begin{array}{l}\text { Há geração de resíduos sólidos durante o processamento? Se existir, informar } \\
\text { quais são os principais controles e/ou destinação dada a cada um dos mesmos. }\end{array}$ & 50 & 50 & - & - \\
\hline A empresa possui estação de tratamento de efluentes industriais? & 25 & - & 50 & 25 \\
\hline $\begin{array}{l}\text { Há geração de emissões atmosféricas durante o processamento? Se existir, } \\
\text { informar quais são as principais medidas de controle existentes. }\end{array}$ & 25 & 25 & 50 & - \\
\hline A empresa possui sistema de gestão ambiental certificado? & - & - & 100 & - \\
\hline
\end{tabular}

*Legenda: $\mathrm{A}$ = Atende, $\mathrm{AP}$ = Atende Parcial, $\mathrm{N}$ = Não Atende e NA = Não Aplicável.

Tabela 3. Situação das empresas na área de responsabilidade social.

\begin{tabular}{|c|c|c|c|c|}
\hline \multirow{2}{*}{ Responsabilidade social } & \multicolumn{4}{|c|}{ Situação das empresas* } \\
\hline & A & AP & $\mathrm{N}$ & NA \\
\hline Há indícios de discriminação por sexo, raça ou idade? & 100 & - & - & - \\
\hline $\begin{array}{l}\text { Todo contingente próprio da força de trabalho ou terceirizado possui carteira } \\
\text { assinada e atualizada? }\end{array}$ & 100 & - & - & - \\
\hline $\begin{array}{l}\text { Eventuais menores aprendizes são contratados com base na legislação vigente } \\
\text { (atenção para aprendizes, dentro das regras legais existentes)? }\end{array}$ & 25 & - & 75 & - \\
\hline $\begin{array}{l}\text { São concedidos benefícios adequados para a força de trabalho própria (cestas } \\
\text { básicas, plano de saúde, seguro contra acidentes, PL etc.)? }\end{array}$ & - & 100 & - & - \\
\hline A empresa possui sistema de gestão de responsabilidade social certificado? & - & - & 100 & - \\
\hline
\end{tabular}

*Legenda: A = Atende, AP = Atende Parcial, $\mathrm{N}$ = Não Atende e NA = Não Aplicável.

Tabela 4. Situação das empresas na área de saúde e segurança.

\begin{tabular}{|c|c|c|c|c|}
\hline \multirow{2}{*}{ Questionário de saúde e segurança } & \multicolumn{4}{|c|}{ Situação das empresas* } \\
\hline & A & AP & $\mathrm{N}$ & NA \\
\hline A empresa possui certificado do Corpo de Bombeiros? & 25 & 75 & - & - \\
\hline A empresa constituiu SESMT (conforme GR e no de funcionários)? & - & - & - & 100 \\
\hline A empresa constituiu a CIPA? & 25 & 50 & 25 & - \\
\hline $\begin{array}{l}\text { Há evidências de registro de acidentes, com ou sem emissão de comunicação } \\
\text { de acidente do trabalho (CAT), nos últimos } 5 \text { anos? }\end{array}$ & - & 50 & 50 & - \\
\hline A empresa possui PCMSO? & - & 50 & 50 & - \\
\hline A empresa possui PPRA? & - & 50 & 50 & - \\
\hline $\begin{array}{l}\text { Transporte, movimentação, armazenamento e manuseio de materiais são } \\
\text { realizados de modo a evitar acidentes? }\end{array}$ & 25 & 25 & 50 & - \\
\hline $\begin{array}{l}\text { As máquinas e equipamentos são dotados de dispositivos de segurança de } \\
\text { parada/partida e acesso? }\end{array}$ & - & 100 & - & - \\
\hline $\begin{array}{l}\text { A empresa disponibiliza sinalização de segurança, incluindo mapa de risco, } \\
\text { para comunicar os riscos à força de trabalho? }\end{array}$ & - & 100 & - & - \\
\hline $\begin{array}{l}\text { Os extintores de incêndio estão disponíveis nos locais de trabalho e são } \\
\text { inspecionados periodicamente? }\end{array}$ & - & 100 & - & - \\
\hline
\end{tabular}


Para cada item do questionário de saúde, segurança, meio ambiente e responsabilidade social foram estabelecidos critérios de aceitação, de modo a facilitar o seu julgamento e permitir a atribuição dos valores Atendido (A), Atendido Parcialmente (AP) ou Não Atendido (N) para cada um dos itens avaliados. Será atribuído o valor Não Aplicável (NA) quando, em comum acordo, for julgado e, devidamente, justificado. Alguns dos critérios de aceitação são apresentados no Quadro 1.

São apresentados na Tabela 1 dois dados; o número de empregados e terceirizados por empresa e a produção anualizada de 2009 das empresas recicladoras, considerando os segmentos de plásticos.

\section{Resultados e Discussões}

\subsection{Avaliação global}

As Tabelas 2, 3 e 4 apresentam um resumo dos questionamentos efetuados e o grau de atendimento delas para cada um dos segmentos avaliados.

\section{Conclusões}

A pesquisa mostrou a falta de conhecimento dos gestores sobre as questões relacionadas à saúde, segurança e socioambientais. Verificou também que as indústrias de processo de reciclagem de plástico não atendem aos requisitos constantes nas normas regulamentadoras do trabalho e na legislação de saúde e segurança.

Apesar de algumas empresas registrarem os acidentes, por meio de comunicação de acidentes de trabalho (CAT), não há uma prática de investigação das causas dos acidentes a fim de evitar reincidência. A comunicação dos riscos das atividades aos funcionários não é realizada por meio de ordens de serviço, conforme previsto na norma regulamentadora NR01. As empresas fornecem equipamento de proteção individual; no entanto, não há programa de inspeção para fiscalizar o seu uso, aumentando a exposição dos trabalhadores aos riscos presentes no ambiente de trabalho.

Programas, como o Programa de Controle Médico e Saúde Ocupacional (PCMSO) e Programa de Prevenção de Riscos Ambientais (PPRA), foram implantados parcialmente em 50\% das empresas, sendo que os mesmos não identificaram todos os riscos físicos, químicos e biológicos do ambiente de trabalho, impossibilitando o diagnóstico precoce de doenças ocupacionais. Além disso, destaca-se ausência de laudos ergonômicos, de programas de qualificação dos eletricistas, de planos de manutenção e de planos de emergência.

Das quatro empresas avaliadas apenas uma afirmou possuir a licença de operação emitida pelo órgão estadual ambiental, porém não foi observado sistema de controle das emissões de compostos voláteis nas zonas de baixa pressão das extrusoras e estações de tratamento de efluentes, que se mostraram mal dimensionadas ou inexistentes.

No que tange às questões sociais, todos os funcionários possuem carteira assinada, além de ser evitado o excesso de horas extras, e, quando se faz necessário, estas são devidamente remuneradas. Entretanto, não foram observadas iniciativas na área de responsabilidade social, tais como plano de saúde para os trabalhadores; remuneração por desempenho da companhia (participações nos lucros - PL); incentivo à educação e qualificação profissional dos seus empregados e familiares dos empregados; aumento da integração com a comunidade, para divulgar os projetos das empresas, através de palestras ministradas por seus funcionários; criação de parcerias com hospitais e creches, para melhoria das mesmas; incentivo a projetos culturais e outros.

Quanto ao sistema de gestão, constatou-se que nenhuma das empresas avaliadas optou por implementar um sistema de gestão de saúde e segurança ou meio ambiente ou responsabilidade social, certificados ou não, permanecendo apenas no gerenciamento das atividades de recebimento, processamento e disposição dos resíduos eventualmente gerados no processo de reciclagem.

\section{Recomendações}

Com base na pesquisa realizada pode-se constatar que o setor de reciclagem deveria ser mais estimulado e principalmente ter o seu reconhecimento como sendo uma atividade imprescindível na questão da preservação do meio ambiente. 0 poder público deveria estimular a atividade, promovendo cursos de capacitação, a exemplo do que vem sendo realizado no Programa de Mobilização da Indústria Nacional de Petróleo e Gás Natural (PROMIMP), instituído pelo governo federal através do Decreto n. ${ }^{\circ} 4.925$, do dia 19 de dezembro de 2003, (BRASIL, 2003) com o objetivo de maximizar a participação da indústria nacional de bens e serviços, em bases competitivas e sustentáveis, na implantação de projetos de petróleo e gás natural no Brasil e no exterior.

0 mesmo estudo deveria ser realizado com o segmento de catadores. Se as perspectivas de crescimento industrial previsto com a operacionalização do pré-sal forem confirmadas, o Estado do Rio de Janeiro vai passar por uma completa 
reforma industrial, sendo prevista a instalação de no mínimo dois polos petroquímicos que certamente irão concorrer para a geração de empresas. Estas serão capazes de disponibilizar, no mercado, materiais recicláveis, e o preparo de mão de obra qualificado viria atender essa futura demanda.

\section{Referências}

ASSOCIAÇÃO BRASILEIRA DE NORMAS TÉCNICAS - ABNT. NBR 16001: Responsabilidade Social - Sistema de Gestão - Requisitos. Rio de Janeiro, 2004a. 11 p.

ASSOCIAÇÃO BRASILEIRA DE NORMAS TÉCNICAS - ABNT. NBR 1SO 14001: Sistemas de Gestão Ambiental Requisitos com Orientações para uso. Rio de Janeiro, 2004b. 27 p.

ASSOCIAÇÃO DOS RECICLADORES DO RIO DE JANEIRO ARERJ. A importância da Reciclagem. 2009. Disponível em: <http://www.arerj.org.br/>. Acesso em: 03 jan. 2009.

BRASIL. Conselho Nacional de Meio Ambiente - CONAMA. Resolução n 237, de 19 de dezembro de 1997. Diário Oficial [da] República Federativa do Brasil, Brasília, DF. 22 dez. 1997. Disponível em: <http://www.siam.mg.gov. $\mathrm{br} / \mathrm{sla} /$ download.pdf?idNorma $=2080>$. Acesso em: 16 jul. 2009.

BRASIL. Lei $n^{\circ}$ 9.605, de 12 de fevereiro de 1998. Lei de crimes ambientais dispõe sobre as sansões penais e administrativas derivadas de condutas e atividades lesivas ao meio ambiente, e dá outras providências. Diário Oficial [da] República Federativa do Brasil, Brasília, DF, 13 fev. 1988. Disponivel em: <http://www.ibama.gov.br/leiambiental / home.htm\#lei_natu>. Acesso em: 07 set. 2009.

GUTBERLET, J.; BAEDER, A. M. Informal recycling and occupational health in Santo Andre, Brazil. International Journal of Environmental Health Research, v. 18, n. 1, p. 1-15, 2008.

INTITUTO ESTADUAL DO AMBIENTE - INEA. Diretriz DZ205.R-5, de 05 de outubro de 1991. Diretriz de Controle de Carga Orgânica em Efluentes Líquidos de Origem Industrial. Diário Oficial do Estado do Rio de Janeiro, Rio de Janeiro, RJ. 24 out. 1991. Disponível em: <http:// www.inea.rj.gov.br/fma/legislacao.asp>. Acesso em: 23 fev. 2009.

BRASIL. Decreto n. 4.925, de 19 de Dezembro de 2003. Institui o Programa de Mobilização da Indústria Nacional de Petróleo e Gás Natural - PROMINP, e dá outras providências. Diário Oficial da União, Brasília, 22 dez. 2003, Seção 1, p. 3.

BRASIL. Ministério do Trabalho e Emprego. Portaria $n^{\circ}$ 3.214, de 08 de junho de 1978. Aprova as Normas Regulamentadoras - NR - do Capítulo V, Título Il, da Consolidação das Leis do Trabalho, relativas à Segurança e Medicina do Trabalho. Diário Oficial da União, Brasília, 06 jul. 1978.

OCCUPATIONAL HEALTH AND SAFETY ASSESSMENT SERIES. OHSAS 18001: Especificação para Sistemas de Gestão de Saúde Ocupacional e Segurança. Reino Unido, 2007.

PAOLIELLO, M. M. B.; DE CAPITANI, E. M. Occupationa and environmental human lead exposure in Brazil. Environmental Research, v. 103, n. 2, p. 288-297, 2007.

PEREIRA, A. M. Estudo da cadeia produtiva da reciclagem de poli(tereftalato de etileno) no Estado do Rio de Janeiro. 2006. 98 f. Tese (Mestrado em Tecnologia de Processos Químicos e Bioquímicos) - Escola de Química - EQ, Universidade Federal do Rio de Janeiro, Rio de Janeiro, 2006.

RIO DE JANEIRO (Município). Decreto n. ${ }^{\circ} 28.329$, de 17 de agosto de 2007. Regulamenta critérios e procedimentos destinados ao Licenciamento Ambiental, à Avaliação de Impactos Ambientais e ao Cadastro Ambiental de atividades e empreendimentos que menciona e dá outras providências. Diário Oficial do Município do Rio de Janeiro, Rio de Janeiro, RJ, 20 ago. 2007, Seção 1, p. 1.

RIX, B. A. et al. Risk of cancer among paper recycling workers. Occupational and Environmental Medicine, v. 54, n. 10, p. 729-733, 1997.

SOCIAL ACCOUNTABILITY INTERNATIONAL - SAl. Social Accontability 8000. United States of America, 2008.

TERASAKl, M. et al. Organic pollutants in paper-recycling process water discharge areas: First detection and emission in aquatic environment. Environmental Pollution, v. 151 , n. 1, p. 53-59, 2008.

\title{
The question of socio-environmental accountability in recycling of plastics in Rio de Janeiro
}

\begin{abstract}
This study aimed to determine how recycling activities impact on health, safety and the environment while also raising some questions related to social responsibility, especially in terms of meeting legislated health, safety and environmental regulatory standards. A questionnaire was developed that was applied directly to a group of recyclers, all located in Rio de Janeiro, three from the Polyethylene and Polyethylene Terephthalate sector. It was found that only $24 \%$ of the items assessed were seen in their entirety, demonstrating a low rate of service issues relating to health, safety and environment and social responsibility. Finally, this study shows that greater attention is needed from the government to create an infrastructure for training in order for information on health, safety, environment and social responsibility to permeate to the professionals who operate in recycling.
\end{abstract}

\section{Keywords}

Recycling. Plastic. Health security. Environment. Social responsibility. 